\title{
Spread spectrum modulation investigation using MATLAB developed tool on automotive DC-DC converter
}

\author{
Sivanyanam Rajamanickam ${ }^{1} \cdot$ Zuccollo Andrea $^{1} \cdot$ Siva Kumar Subramaniam $^{2} \cdot$ Zamre bin ABD Ghani $^{2}$ \\ ${ }^{1 *)}$ Fakulti Kejuruteraan Elektronik dan Kejuruteraan Komputer, Universiti Teknikal Malaysia Melaka; \\ 1) Advance Sensors \& Embedded Controls System (ASECS), \\ Centre for Telecommunication Research \& Innovation (CeTRI), \\ Fakulti Kejuruteraan Elektronik dan Kejuruteraan Komputer, \\ Universiti Teknikal Malaysia Melaka, Malaysia. \\ *Corresponding e-mail: sivanyanam.Rajamanickam@infineon.com,siva@utem.edu.my
}

\begin{abstract}
Electromagnetic Interference (EMI) classified as emission from a device or a system that interrupt normal operation of the own or neighbor system. Generally, EMI is caused by radiation emitted from an external source. The electromagnetic interference classified into conducted emission and radiated emission. Conducted EMI is pass through transmission lines such as wires and PCB traces whereas radiated EMI is caused by induction. Nowadays, spread spectrum concept widely used in design phase of DC-DC converter as a measure to keep emission within automotive EMC defined standard besides filter techniques and PCB designs. In principle, there are many different test measurement setup used in spread spectrum modulation concept for conducted EMI analysis which cause beginners difficult to master the topic. This paper describes a developed MATLAB program for spread spectrum modulation (SSM) techniques with several modulation parameters, profiles, including test measurement setups in EMI analysis.
\end{abstract}

Key words: SSM; EMI reduction; DC-DC converter; MATLAB

\section{INTRODUCTION}

In the advancing semiconductor industry, the demand for DC-DC converters increases dramatically to cater to high current application in the automotive industry [1]. The DC-DC converter used to step up or step down battery voltage to produce a sustainable power supply line, working to protect the line's stability to be used as a power supply to other application in the vehicle such as sensors, microcontrollers, electronic control units (ECUs) or even other connected electronics components as shown in Figure 1.

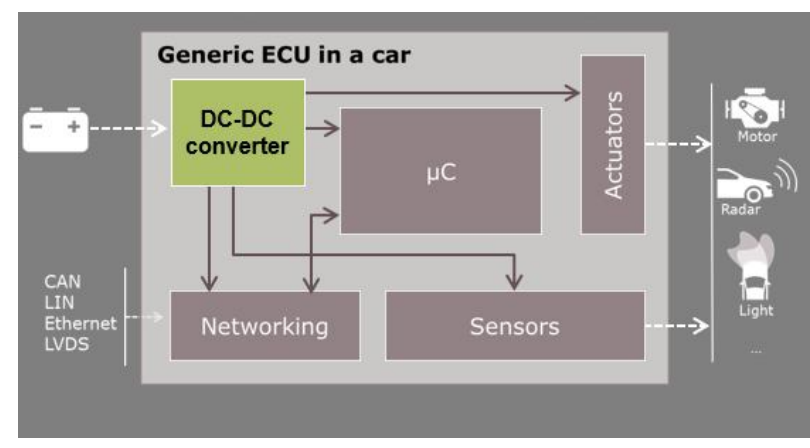

Figure 1: Automotive electronics system structure of DC-DC converter as a power supply.

There is a big challenge in DC-DC converter design phase due to tough and complex requirement in supply modules such as smaller in footprint, higher current capability and it needs to be fast [2]. During the design phase, signal integrity and EMI must comply with automotive EMC standard according to its region. During the fast switching operation mode, DC-DC converters generates high-frequency noise [3]. This generated noise known as conducted interference since it transmit through the power lines and might cause interference to other electronic systems in the vehicle.

International Electrotechnical Commission (IEC), Society of Automotive Engineers (SAE) and the International Organization for Standardization (ISO) which are automotive EMC standard chartered by the United Nations. International Special Committee on Radio Interference (CISPR) 25 standard is to ensure that receivers used in vehicles such as boats, and internal combustion engines are protected within compliance. Hence ISO 11452-2 standard applies on higher frequencies from $200 \mathrm{MHz}$ to $18 \mathrm{GHz}$ range [4-5]. This is an immunity standard which applies to military and aerospace standards. 


\section{BACKGROUND WORKS}

Electromagnetic compatibility (EMC) is an important scope with major challenge for equipment and switching mode power supply manufacturers. EMC compliance of a product has become a major factor defining its acceptance in the market since respective market/countries have their own standard. The EMC challenge has divided into two parts:

- Suppression of interferences at the source level.

- Ensure designed devices or systems immune to EMI.

\subsection{Electromagnetic Compatibility Susceptibility and Immunity}

EMC susceptibility classified as the tolerance of circuits and components to all sources of interfering electromagnetic energy. There are several measures used to suppress the unwanted emission such as design, filter techniques, shielding at source level $[6,7]$.

The background of the immunity test is that to assess if the device has a high tendency to expose with various types of electric field disturbances in the application. It can be a mobile signal or it might place closed to any motor application where the electric field sources interact with our device. Theoretically, EMC immunity defined as an ability of a device to withstand different types of electromagnetic phenomena. This is vital for consumer goods in automotive, military, medical, avionics and other fields.

There are three approaches used for EMI suppression [36]:

- Filter technique on power and signal lines to suppress the conducted EMI.

- Good shielding for radiated EMI.

- Proper grounding

\subsubsection{EMI Filter}

Generally, conducted emission is minimize by adding a filter within low-frequency bands. There are alternate options such as the passive filter and the active filter used in circuity [8]. The commonly used passive filters as shown in Figure 2. However, for radiated EMI, shielding technique used when it is within high-frequency bands. Theoretically, filter approach is restricted in a narrow frequency band but not suitable for wider EMI frequency band [9-11]. Therefore, a few stages of filters should be considered which leads to complex board design. This approach does not only increase the cost of the system, but also give impact on printed circuit board (PCB) dimension and weight, and portability. In this scenario, proper layout design strategies is necessary to eliminate the EMI problem [12].

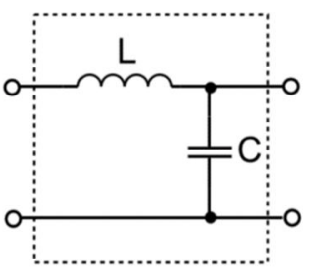

a)

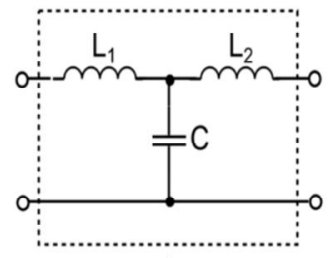

c)

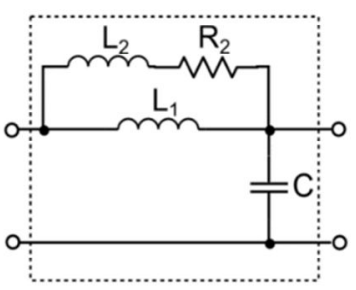

e)

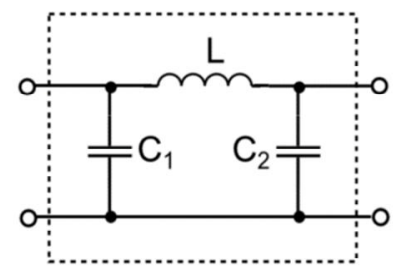

b)

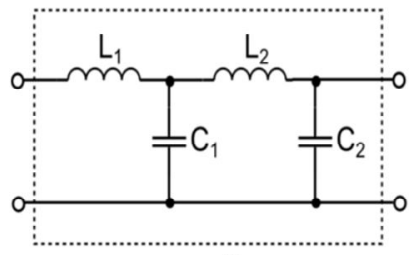

d)

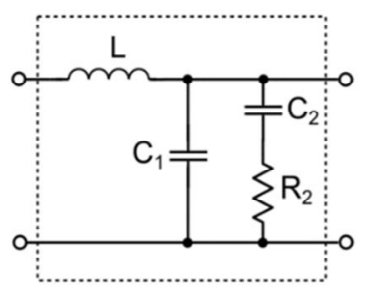

f)

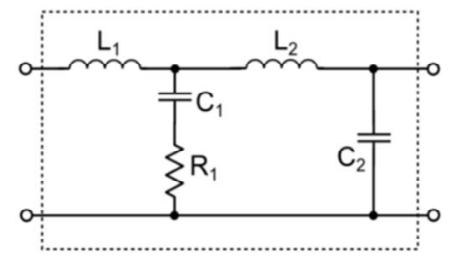

g)

Figure 2: Passive external filter topologies

Since power electronics now getting into higher complexity with more features, EMI filters are becoming one of the key element in the DC-DC converters. For common mode (CM) EMI filters, big inductance required due to the maximum $\mathrm{CM}$ capacitance which is limited by the safety standards. Usually, $\mathrm{CM}$ inductors are bulky and heavy because the inductor windings drive maximum current [13-15]. However, the hybrid filter (HEF) is a combination of an active filter and a passive filter. The active filter applied to reduce low-frequency EMI noise and the passive filter mainly for high-frequency noise. The passive filter size is significantly reduced because the passive filter has a much wider frequency range than a conventional EMI filter. In nutshell, total size and weight can be optimized with implementation of active and passive filters. [14], [16]. At the same time, the HEF as shown in Figure 3 have a better efficiency in filtering due to the better high-frequency performance of passive filter. Moreover, it has reduced parasitic parameters [17]. 


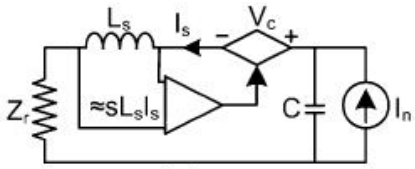

(a)

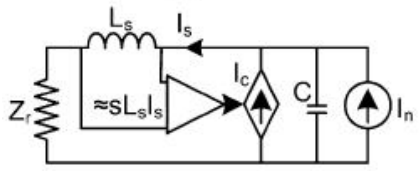

(c)

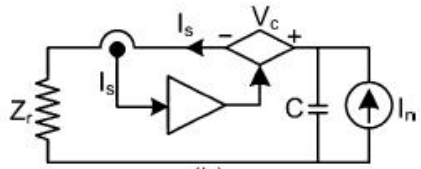

(b)

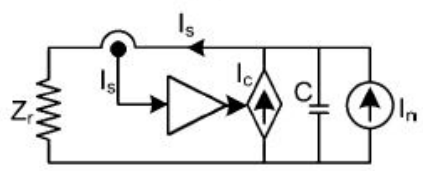

(d)
Figure 3: Feedback Active External Filter topologies

\subsubsection{EMI shielding technique}

Shielding technique used to limit the radiation of electromagnetic emission into space with barrier made of conductive material. Typically, it is applied as enclosures, separating electrical devices from the external influence. By the way for cables, separating wires from the environment, through the shielded insulator. Shielding is a fast and effective method but it is expensive solution for EMI suppression. Due to this, both above-discussed approaches are not perfect solutions for emission suppression because in practical there are many possibilities for leak sources on the enclosures.

\subsubsection{EMI spread spectrum modulation technique}

Typically, the main contribution of emission in DC-DC converters generates from a certain pattern of PWM during the switching of a DC voltage. Usually with square or sawtooth wave a constant switching frequency and with a variable duty cycle $\left(D=t_{D n} / T\right)$. Noise at low frequency is most significant contributions to the EMI spectrum. Basically, this is known as fundamental switching frequency. Commutation process leads to presence of other emission components at higher frequencies and the total emission can be evaluated as explained in reference [18]. The main interferences at low frequencies is able to minimise by modifying control signals, $V_{s}\left(f_{5}, D\right)$. A spectrum with lower peak amplitude than the constant frequency of triangular or Hershey-kiss signal, meantime keeping the desired duty, $\boldsymbol{D}$. Spread Spectrum Frequency Modulation (SSFM) concept used to control signal by applying variable switching frequency. In SSFM, the initial energy of each harmonic is spread into a band of frequencies, B, up and down the base value, giving a wider spectrum with lower amplitudes. Figure 4 shows the comparison between the spectrum of a pure sinusoidal signal of frequency $f c$, and the spectrum of the same signal modulated with certain $\Delta f c$.

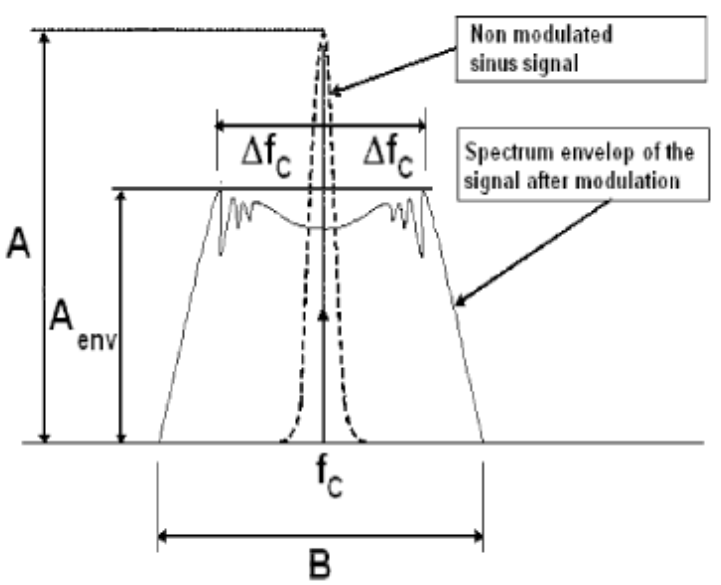

Figure 4: Spectrum of a sinus signal with FM following a sinus variation in time.

The maximum amplitude, $A_{\text {enw }}$, which is coming from spectrum significantly lower than the amplitude, $A$, of the reference signal. For square signals, the spectrum of each harmonic suffers the effects of modulation. It resulting spectrum from the different harmonic bands, as shown in Figure 5.

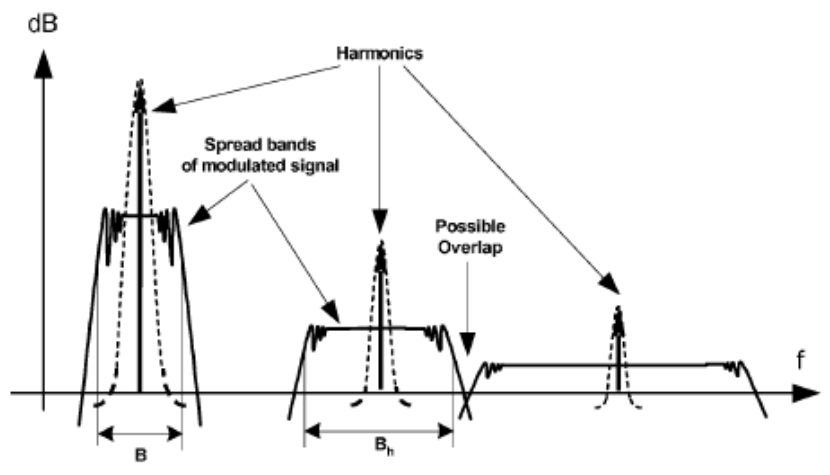

Figure 5: Spread bands of the different harmonics when SSFM is applied to a square signal

The initial works using SSFM in order to reduce EMI studied on communications and microprocessor systems in nineties [19] to [22]. A similar concept was tried on switching DC-DC converters by F. Lin and D.Y. Chen, from Virginia Power Electronics Center (VPEC) [23-28]. Nevertheless, many research works applying SSFM to DC-DC converters, used various modulation profiles such as sinusoidal and random, but authors did not extend in-depth the effects of possible modulation with other periodic profiles. In [29] to [31], the authors proposed the use of modulation techniques following certain periodic patterns (exponential, sinusoidal and triangular) for the frequency deviations, see Figure 6. In such publications, the theoretical basis of SSFM using periodic profiles was established and the method was applied on the PWM control signal. The triangular profile showing that 
maximal flat spectrum can be obtained and that selective cancellation of harmonics is possible with certain exponential profiles [28]. In this research work, comparison between the theoretical and experimental results of [29] to [30] with experimental results measured at the supply of a low power $(2,5 \mathrm{~W})$ buck converter switching at $f_{c}=1 \mathrm{MHz}[35]$.

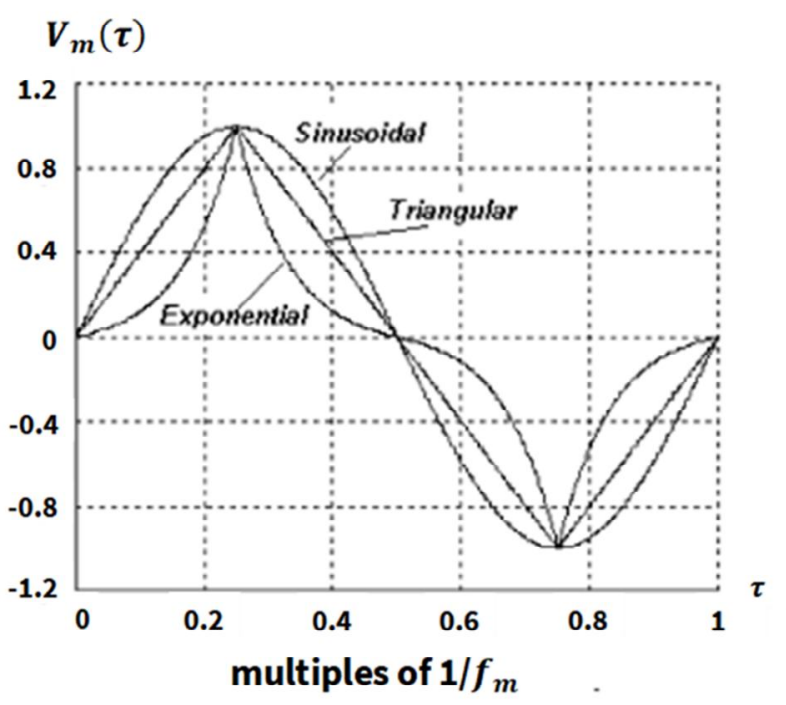

Figure 6: Change rate of frequency in modulation profiles.

Nowadays, the EMI issue has been tackled by spread spectrum approach by employing various modulation profiles according to design. However, there exist prominent problem on DC-DC converters such as ripples of the output waveforms are higher than periodically running supplies which is degrading DC power supplies; and the other one is that the parameter design of DC-DC converters becomes challenging due to the frequency variation under modulation approach.

\section{METHODOLOGY}

The ultimate goal for the development of this MATLAB tool is to provide a very comprehensive analysis framework, which is not bound to the Cadence, for benchmarking the proposed spread spectrum techniques, and also to obtain the best combination of parameter values by applying these techniques. In the literature part, Discrete Fourier Transform to a frequency modulated tone are applied in analysis. Theoretically, this method can be proved that when a spread spectrum modulation technique is applied to a tone, the resulting spectrum is spread over a frequencies range and the reduction can be seen on the maximum value of the power spectrum.

\subsection{Graphical User Interface Outline}

As shown in Figure 7, the developed MATLAB program to understand and perform spread spectrum modulation techniques on a switching mode power supply. This program classified into four different types of analysis mode such as conducted emission from a generic switching circuit conducted emission from buck input circuitry conducted emission from the output and the last mode is frequency domain analysis of a carrier frequency spread spectrum modulation. This paper mainly describes the analysis of buck emission with Line Impedance Stabilization Network (LISN) test setup based on CISPR 25 standard, frequency domain analysis of a carrier frequency spread spectrum analysis and its outcomes.

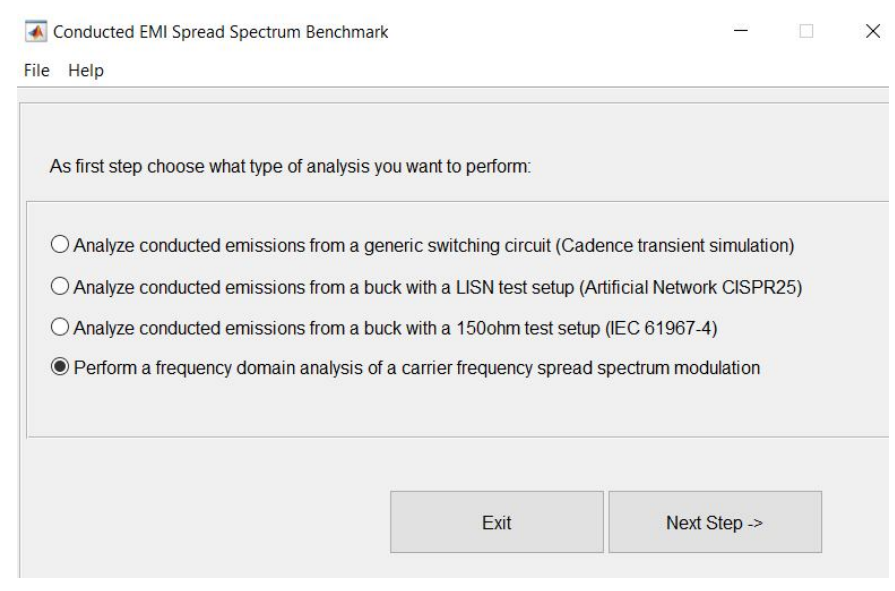

Figure 7: Graphical User Interface (GUI) of the MATLAB tool

\subsection{Buck Simulation Setup using a LISN test setup (CISPR 25)}

This sub-application developed to emulate measurement using an EMI receiver of the conducted EMI emission produced by a buck converter. In addition, this tool able to analyse the parameter values to reduce this conducted emission using a spread spectrum modulation method. For the second sub-program developed for CISPR 25 LISN test setup and measurement setup shown in each program accordingly. In the first case, there is represented a LISN network between the battery and the buck together with an input RC filter. This RC filter have option to enable or disabled. LISN is standard proven setup which is widely used for conducted emissions to battery measurement test setup $[32,33]$.

The DC-DC step-down converter is developed through a Simulink model with each block consist of buck, PID controller and SSCG using Time Discrete Model. Simulated or measured time domain data is processed to give an EMI receiver result in the frequency domain. Basically, measured or simulated data fed in the time domain as well as the appropriate settings in order the application computes an emulation of the results in the frequency domain. It is able to display the result in a diagram and to export it. 
The GUI is composed of five parts:

- Configuration of Buck.

- Configuration of PID controller.

- Configuration of Spread Spectrum Clock Generator.

- $\quad$ EMI receiver settings.

- Output settings.

In this part, the user has the flexibility to modify several variables such as spread spectrum modulation profiles, controller and also component values. With this possibility, the user able to investigate the buck performance and emission at the input of buck as describes in Figure 8.

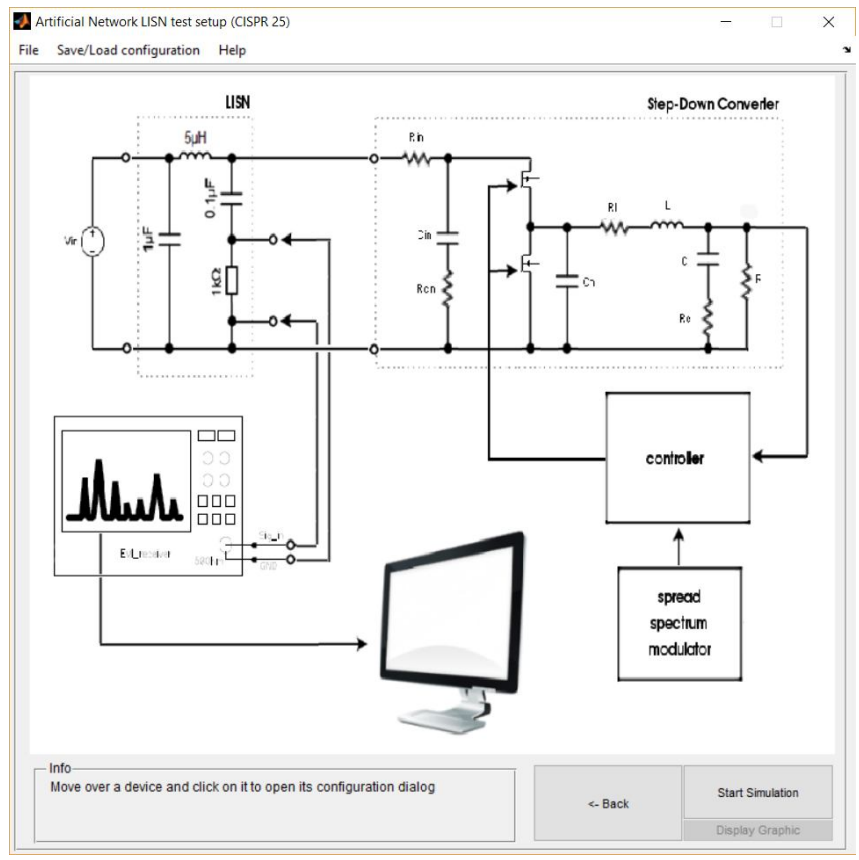

Figure 8: A buck with LISN test setup (CISPR 25)

SSM is a wide and complex topic to be understood by beginners. The last sub-program which shown in Figure 9 used to analyse the influence of spectrum of a tone with a spread spectrum modulation applied by the tool. The modulation profiles is applied through a real scanning receiver instrument emulation. Below GUI consists of four parts:

-Carrier tone pattern

-Spread Spectrum Clock Generator configuration

-EMI receiver settings

-Output settings

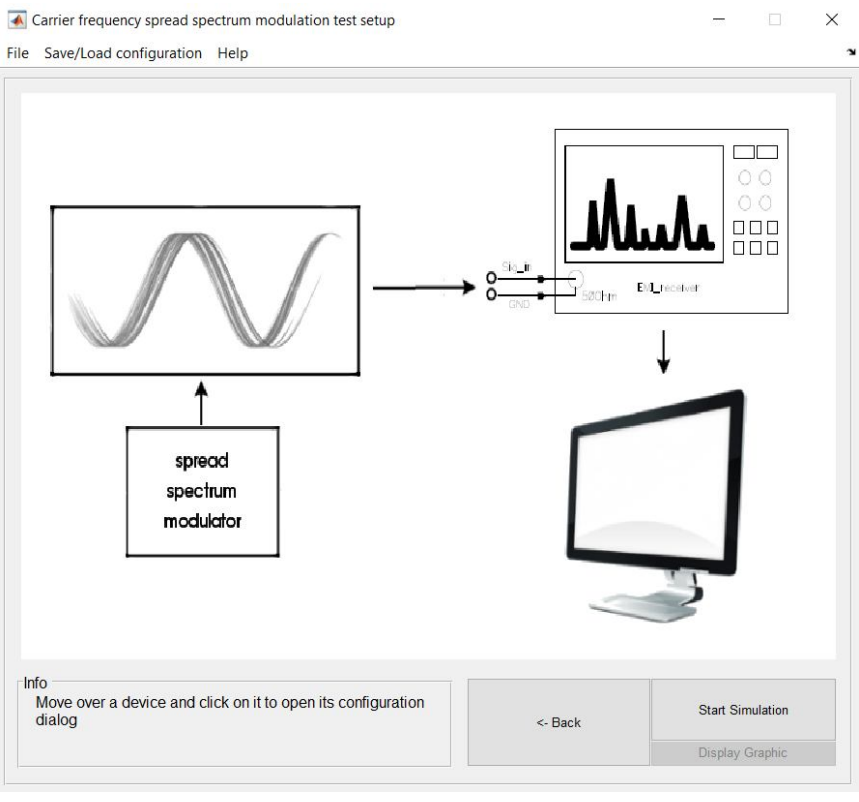

Figure 9: Carrier Frequency setup interface

The modulation profile process output can be expressed in the following equation 4.1 :

$F(t)=A(t) \cdot \cos \left[\omega_{c} \cdot t+\theta(t)\right.$

Where

$\theta(t)=\int_{a}^{2} k_{\omega} \cdot v_{m}(t) \cdot d t \mid \theta(0)$

A working hypotheses is of application in the whole further calculations, defining $V_{m}$ as the peak value of the modulating signal $v_{m}(t)$, the product $k_{\omega} \cdot V_{m}$ expresses the maximum peak deviation of the pulsation $\omega_{2}(t)$ respect to the central pulsation $\omega_{c}$, that is shown in equation 4.2:

$\Delta \omega_{c}=2 \pi \Delta i_{c}^{n}=k_{i e} \cdot V_{m}$

The frequency modulation can be computed using MATLAB code. In the below Figure 10, shows few examples of implemented modulation profiles and their time integrals $\theta(t)[31]$. 

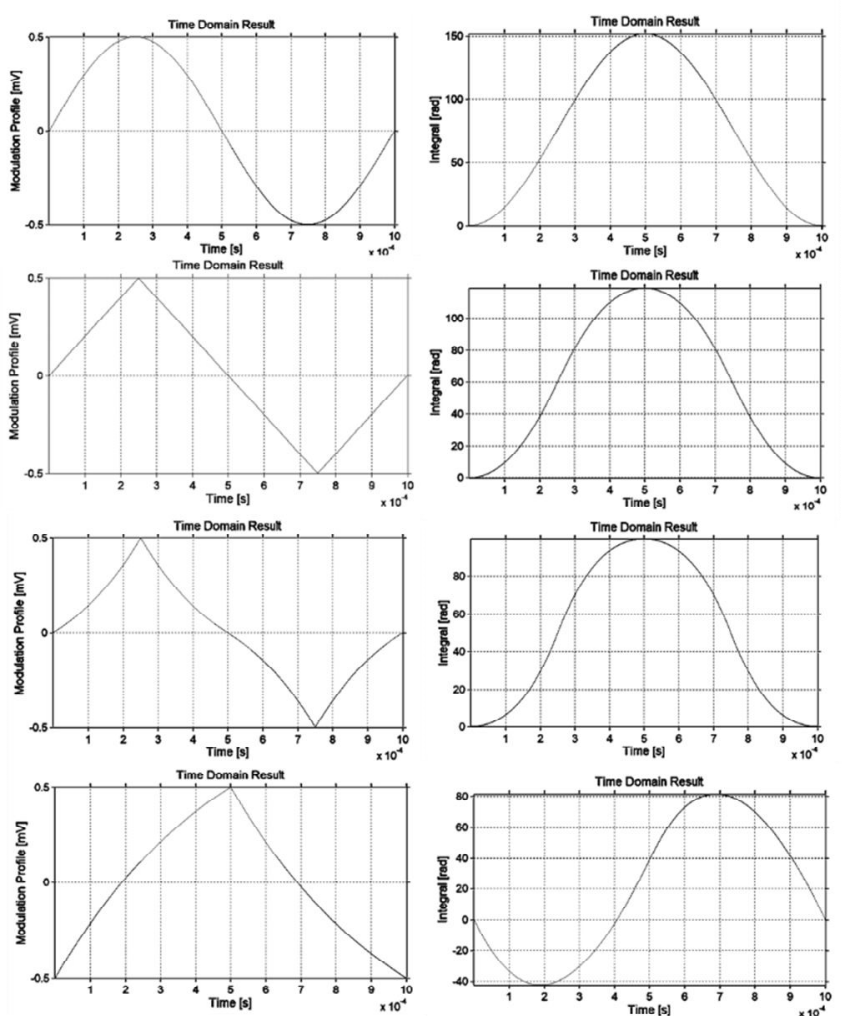

Figure 10: Different types of modulation profile such as sinusoidal, triangular, Hershey-kiss and Sharkfin.

\section{RESULT AND DISCUSSION}

In this section, comparison between the spectral contents of the conducted emissions at input stage (from the buck converter to a battery) were analysed by applying different modulation profiles. Referring to CISPR 25 standard, all these simulation carried out using LISN test setup. Following comparison were used to understand the best profile to apply subsequently for our DC-DC converter application as a measure to reduce EMI.

Figure 11 showed unmodulated signal from LISN test setup. The spikes from unmodulated signal high tendency to fail EMC test.

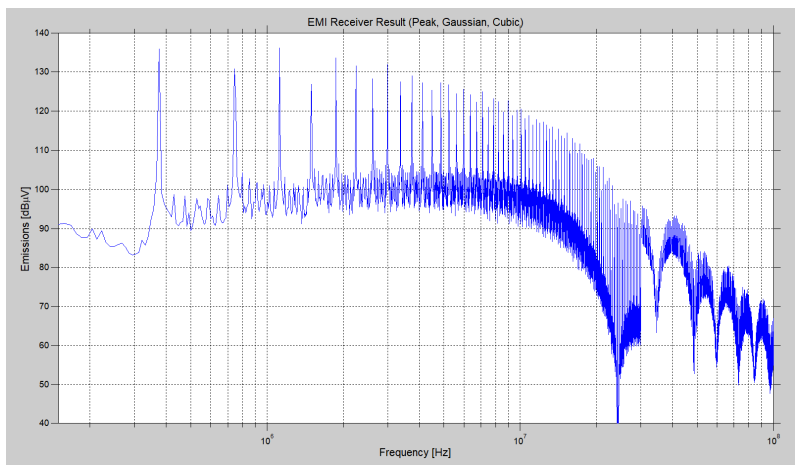

Figure 11: Simulation results without modulation technique.
The simulation performed on triangular and the multi-triangular modulation profile and the outcome compared with the conductive emission resulting from a buck without activating modulation technique. First simulation outcome shows significant improvement can be achieved with spread spectrum techniques. With the above selected modulation parameters there is improvement about $9 \mathrm{~dB}$ on the carrier tone window. There are several other settings can used to further optimized the gain, increasing the spreading percentage is the one of the method. The default switching frequency used was $\mathrm{fc}=380 \mathrm{kHz}$, and the frequency spreading $\mathrm{fc}=76 \mathrm{kHz}$ that with a center spreading give a spreading of $40 \%$. The outcome from triangular and multi-triangular as shown in Figure 12.

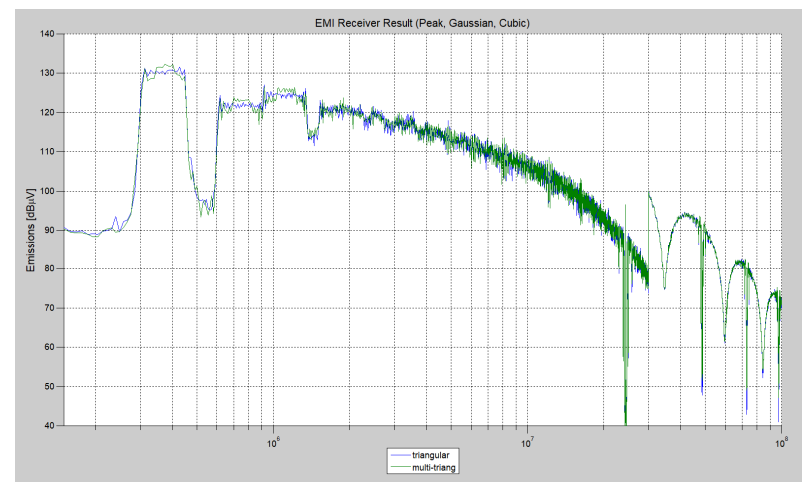

Figure 12: Simulation comparison between the triangular and the multi-triangular profiles.

In subsequent diagrams, more modulation profiles were analyzed. In Figure 13 the result of a spread spectrum modulation from a Hershey-kiss, sharkfin and a compensated profile are shown. From different articles in literature, the Hershey-kiss profile seems to be the most recommended modulation profile but this can be vary based on application.

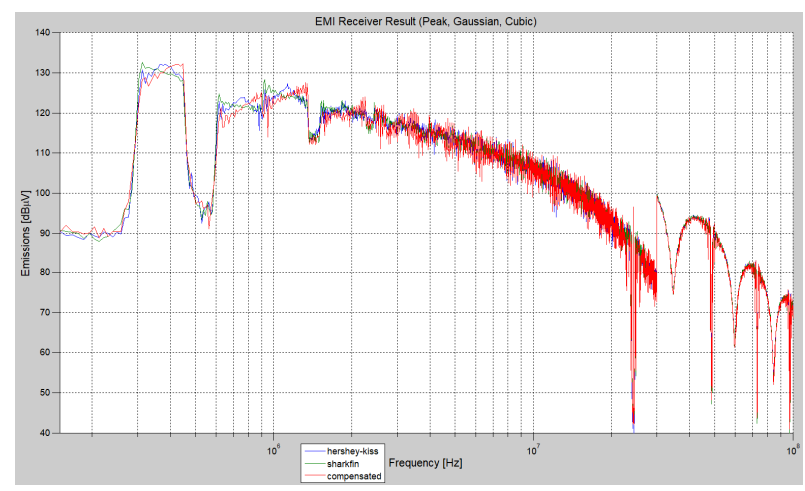

Figure 13: Simulation comparison between the Hershey-kiss, Sharkfin and Compensated. 
For theoretical comparison, additional 3 different modulation profiles (sinusoidal, triangular, Hershey-kiss) simulation has been performed [12]. Figure 14 and 15 are shown the spectral density of a spread spectrum modulated carrier tone. The side-band harmonics of sinusoidal modulation tend to accumulated at the two peaks which defining the side-band harmonics bandwidth. This resulted modulation index $\mathrm{mf}$ high and in the shape of the modulation spectrum envelope showing two peaks at both ends of the bandwidth while the envelope gets a larger concavity between these two peaks. However for triangular modulation profile, the forming of the side-band harmonics corresponds to a nearly flat compared with sinusoidal modulation characteristic [12]. Additionally, Hershey-kiss side-band harmonics outcome quite similar to triangular whereby the concentration around the carrier frequency, and also reduce in amplitude as the side-band harmonic in order separates from the carrier frequency [31, 34].

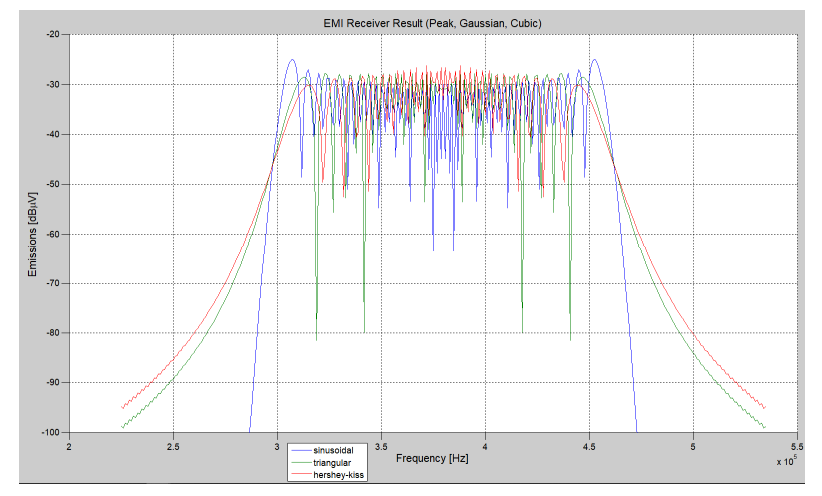

Figure 14: Carrier simulation results with disabled spectrum analyser emulation.

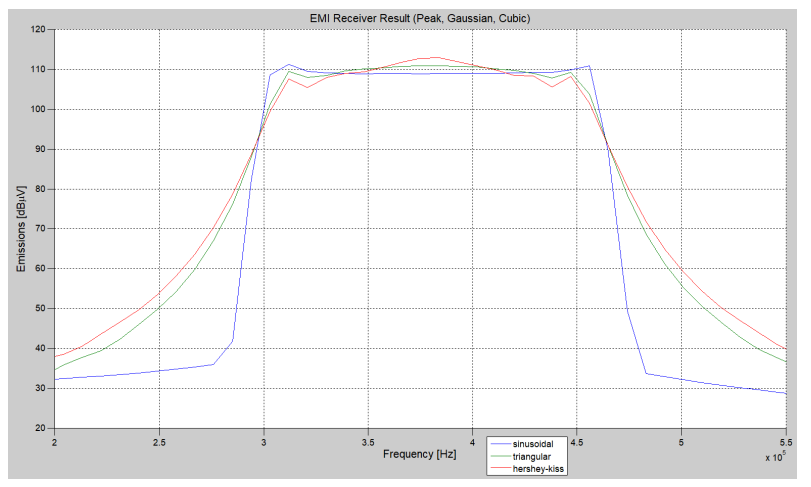

Figure 15: Carrier simulation results with enabled spectrum analyzer emulation.

In addition, comparison between multi-triangular with Hershey-kiss modulation profiles has been performed. Both shows comparable output as shown in Figure 16.

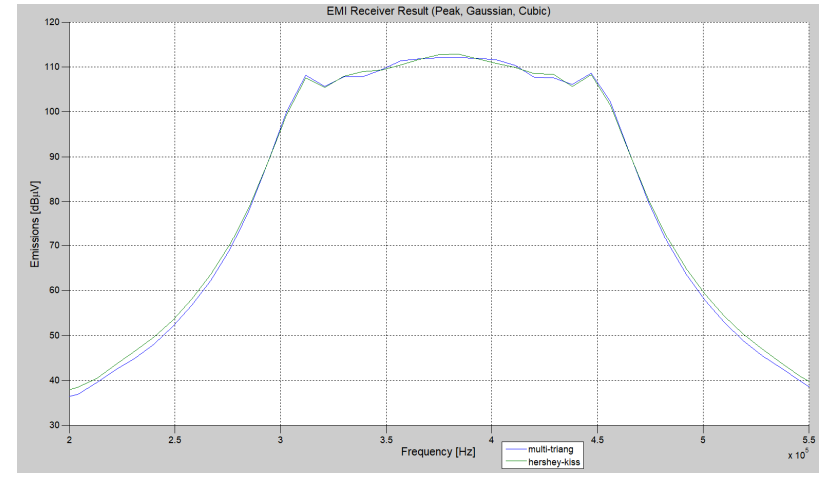

Figure 16: Carrier simulation results with enabled spectrum analyser emulation.

\section{CONCLUSIONS}

This developed MATLAB based tool enables us to simulate the SSM techniques in different measurements setup reference to EMC standard. Based on various simulated modulation profiles after considering the global characteristic of the modulation, the most focus point is the peak value of the envelope. Since it's a global characteristic: the maximum amplitude along with the whole spectrum distribution as a result of a frequency modulation where all harmonic amplitudes will be under this value. Flat harmonic distribution outcome shows that a triangular or Hershey-kiss modulation profile is the suitable for most of the application. Basically, sinusoidal profile shows weak performance due to two sharp edges pattern of the side-band harmonic distribution. In the conclusion, the final reduction on the conductive EME can be vary by the modulation parameters and by the normative parameters of the measurement instrument, like the resolution bandwidth and detector's type in a scanning receiver.

\section{REFERENCES}

[1] V. Tarateeraseth, I.A. Maio, F.G. Canavero, "Assessment of Equivalent Noise Source Approach for EMI Simulations of Boost Converter", Proceedings, 20th Int. Zurich Symposium on EMC, Zurich 2009.

[2] Ghaed Mohammad Hassan, et al. "Circuits for a cubic-millimeter energy-autonomous wireless intraocular pressure monitor." IEEE Transactions on Circuits and Systems I: Regular Papers, vol. 60, no. 12, pp. 3152-3162, Nov. 2013

[3] Krishna Mainali and Ramesh Oruganti, "Conducted EMI Mitigation Techniques for Switch-Mode Power Converters: A Survey," IEEE Transactions on Power Electronics, vol. 25, no. 9, Sep. 2010.

[4] P.Andersen, An overview of automotive EMC standards", IEEE International Symposium on Electromagnetic Compatibility, 2006. 
[5] Code of Federal Regulations 47 (47CFR), Part 15, Subpart B: Unintentional Radiators. [Online]. Available: http://www.ecfr.gov/, accessed Dec. 1, 2015.

[6] M. Terasaki, et al. "Design and Analysis for Noise Suppression of DC/DC Converter." IEEE Electrical Design of Advanced Packaging \& Systems Symposium (EDAPS), pp. 109-112, Dec. 2014.

[7] Kyoungchoul Koo, et al. "Impact of pcb design on switching noise and emi of synchronous dc-dc buck converter," 2010 IEEE International Symposium on Electromagnetic Compatibility (EMC) , pp. 67-71. July 2010. https://doi.org/10.1109/ISEMC.2010.5711249

[8] M. Ali, E. Laboure, and F Costa, "Integrated active filter for differential mode noise suppression," IEEE Trans. Power Electron., vol. 29, no. 3, pp. 1053-1057, Mar. 2014.

[9] C. R. Paul, "A New Method to Characterize EMI Filters," in proc. IEEE Applied Power Electronics Conference, Anaheim, CA, 15-19 Feb. 1998, pp. 929 -933.

[10] F. Y. Shih, D. Y. Chen, Y. P. Wu and Y. T. Chen, "A Procedure for Designing EMI Filters for AC Line Applications", IEEE Trans. on Power Electronics, vol. 1, $\mathrm{N}^{\circ}$ 1, Jan. 1996, pp. 170-181.

[11] H. Chen, Z. Qian, Z. Zeng, C. Wolf, "Modeling of Parasitic Inductive Couplings in a Pi-Shaped Common Mode EMI Filter", IEEE Transactions on Electromagnetic Compatibility, Vol. 50 , No 1, Fab. 2008, pp. $71-79$.

[12] S. Shahparnia and O. M. Ramahi, "Electromagnetic interference (EMI) reduction from printed circuit boards (PCB) using electromagnetic bandgap structures," IEEE Trans. Electromagn. Compat., vol. 46, no. 4, pp. 580 587, Nov. 2004.

[13] R. P. Clayton, Introduction to Electromagnetic Compatibility, 2nd ed.Hoboken, NJ, USA: Wiley, 2006.

[14] S. Wang, Y. Y. Maillet, F. Wang, D. Boroyevich, and R. Burgos, "Investigation of hybrid EMI filters for common-mode EMI suppression in a motor drive system," IEEE Trans. Power Electron., vol. 25, no. 4, pp. 1034-1045, Apr. 2010.

https://doi.org/10.1109/TPEL.2009.2033601

[15] W. Chen, W. Zhang, X. Yang, Z. Sheng, and Z. Wang, "An experimental study of common- and differential-mode Active EMI filter compensation characteristics," IEEE Trans. Electromagn. Compat., vol. 51, no. 3, pp. 683-691, Aug. 2009.

[16] W. Chen, X. Yang, and Z. Wang, "An active EMI filtering technique for improving passive filter low-frequency performance," IEEE Trans. Electromagn. Compat., vol. 48, no. 1, pp. 172-177, Feb. 2006.

[17] Li, H., Ding, Y., Yang, Z. and Jiang, Y., 2019, May. Optimization Design of EMI Filter with Chaotic PWM in DC-DC Converters. In 2019 IEEE Workshop on Wide Bandgap Power Devices and Applications in Asia (WiPDA Asia) (pp. 1-6). IEEE.

https://doi.org/10.1109/WiPDAAsia.2019.8760318

[18] J. Balcells, D. GonzMlez, M. Lamich, D. Bedford, "EMI Generation Models for Switched Mode PowerSupplies"; Proceedings of ESA SP-416, European Space Power
Conference, ISBN 92-9092-664-3, European Space Agency (ESA), Tarragona, Sept 1998

[19] Keith B. Hardin, John T. Fessler and Donald R. Bush, "Spread Spectrum Clock Generation for the Reduction of Radiated Emissions", IEEE Symposium on EMC , 1994 (Chicago).

[20] Cornelis D. Hoekstra, "Frequency Modulation of Systems Clocks for EMI reduction", Hewlett-Packard Journal, August 1997.

[21] Keith B. Hardin, John T. Fessler, Nicole L. Webb, John B. Berry, Andrew L. Cable and Mike J. Pulley, "Design Considerations of Phase-Locked Loop Systems for Spread Spectrum Clock Generation Compatibility", IEEE Symposium on EMC, 1997 (Austin, Texas).

[22] Keith B. Hardin, Robert A. Oglesbee and Fred Fisher, "Investigation Into the Interference Potential of Spread-Spectrum Clock Generation to Broadband Digital Communications", IEEE Transactions on Electromagnetic Compatibility, Vol. 45, No. 1, February 2003

[23] F. Lin and D.Y. Chen, "Reducing of Power Supply EMI Emission by Switching Frequency Modulation", IEEE Transactions on Power Electronics, Vol. 9, January 1994

[24] K.K Tse, Henry Shu-Hung Chung, S.Y.(Ron) Hui, H.C. So "Analysis and Spectral Characteristics of a Spread SpectrumTechnique for conducted EMI supression" ; IEEE Transactions on Power Electronics, Vol. $15 \mathrm{~N}^{\circ}$ 2, March 2000 [25] Giral, H., El Aroudi, A., Martinez-Salamero, 1., Leyva, R., Maixe, J., "Current control technique for improving EMC in power converters", IEE Electronics Letters, 1st March 2001, Vol.37, No.5.

https://doi.org/10.1049/el:20010200

[26] Sadamura, H., Daimon, T., Shindo T., Kobayashi, H., Myono, T., Suzuki, T., Kawai, S., lijima, T., "Spread Spectrum Clocking in Switching Regulators to Reduce EMI", Third IEEE Asia-Pacific Conference on ASICs (AP-ASIC), Taipei, Taiwan, August 6-8, 2002

[27] Analog Devices, Inc., "Implementing Random Space Vector Modulation with the ADMCF32X". Application Note ANF32X-54. December 2002

[26] K.K. Tse, Raymon Way-Man Ng, Henry Shu-Hung Chung, S.Y. Ron Hui, "An Evaluation of the Spectral Characteristics of Switching Converters With Chaotic Carrier-Frequency Modulation", IEEE Transactions on Industrial Electronics, Vol.50, Nil, February 2003.

[27] A. Santolaria, J. Balcells, D. Gonzailez, "Theoretical \& Experimental Results of Power Converter Frequency Modulation", Proceedings of 28th Annual Conference of the IEEE Industrial Electronics Society, IECON 2002, Sevilla, Spain

[28] F. Pareschi, G. Setti, R. Rovatti, and G. Frattini, "Practical optimization of EMI reduction in spread spectrum clock generators with application to switching DC/DC converters," IEEE Trans. Power Electron., vol. 29, no. 9, pp. 4646-4657, Sep. 2014.

[29] A. Santolaria, J. Balcells, D. Gonzailez, J. Gago, "Evaluation of Frequency Modulation in EMI Emissions 
Reduction applied to Switching Power Converters", 29th Annual Conference of the IEEE Industrial Electronics Society, IECON 2003, Virginia, USA.

[30] A.Santolaria, D. Gonzalez, J. Gago, J. Balcells, S. Brehaut, J.C Le Bunetel, D. Magnon; "Periodic Frequency Modulation Applied to Noise Cancellation between Power and Communication Buses", 16th EMC International Symposium, Zurich, February 2005

[31] F. Pareschi, G. Setti, R. Rovatti, and G. Frattini, "Short-term optimized spread spectrum clock generator for EMI reduction in switching DC/DC converters," IEEE Trans. Circuits Syst. I, Reg. Papers, vol. 61, no. 10, pp. 3044_3053, Oct. 2014.

[32] Crebier, J.C., Roudet, J. and Schanen, J.L., 1999, July. Problems using LISN in EMI characterization of power electronic converters. In 30th Annual IEEE Power Electronics Specialists Conference. Record.(Cat. No. 99CH36321) (Vol. 1, pp. 307-312). IEEE.

[33] Stahl, J., Kuebrich, D., Bucher, A. and Duerbaum, T., 2010, September. Characterization of a modified LISN for effective separated measurements of common mode and differential mode EMI noise. In 2010 IEEE Energy Conversion Congress and Exposition (pp. 935-941). IEEE.

[34] Pareschi, F., Rovatti, R. and Setti, G., 2015. EMI reduction via spread spectrum in DC/DC converters: State of the art, optimization, and tradeoffs. IEEE Access, 3, pp.2857-2874.

[35] J. Balcells, D. Gonzalez, J. Gago, A. Santolaria, J.C. Le Bunetel, D. Magnon, S. Brehaut. "Frequency modulation techniques for EMI reduction in SMPS", 2005 European Conference on Power Electronics and Applications, 2005 https://doi.org/10.1109/EPE.2005.219198

[36] J. Chen, D. Jiang, W. Sun, Z. Shen and y. zhang, "A family of spread-spectrum modulation schemes based on distribution characteristics to reduce conducted EMI for power electronics converters," in IEEE Transactions on Industry Applications, doi: 10.1109/TIA.2020.3002472. 